Research Paper

\title{
Resveratrol reduces inflammation-related Prostate Fibrosis
}

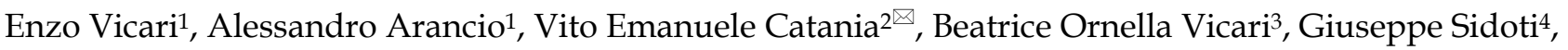 \\ Roberto Castiglione ${ }^{1}$, Michele Malaguarnera ${ }^{3}$ \\ 1. Department of Clinical and Experimental Medicine, University of Catania, 95123 Catania, Italy. \\ 2. Department of Medical, Surgical Sciences and Advanced Technologies "G.F. Ingrassia”, University of Catania, 95123 Catania, Italy. \\ 3. Research Centre "The Great Senescence", University of Catania, 95126 Catania, Italy. \\ 4. UOSD Medicina Interna Ambulatorio Andrologia \& Endocrinologia ARNAS-Garibaldi, 95123 Catania, Italy. \\ $\square$ Corresponding author: Prof. Vito Catania via Santa Sofia 78, 95123 Catania; E-mail: vito.catania@policlinico.unict.it. \\ (c) The author(s). This is an open access article distributed under the terms of the Creative Commons Attribution License (https://creativecommons.org/licenses/by/4.0/). \\ See http:/ /ivyspring.com/terms for full terms and conditions.
}

Received: 2020.01.31; Accepted: 2020.05.12; Published: 2020.07.19

\begin{abstract}
Inflammation-related prostate fibrosis (PF) is strongly associated with impaired urethral function and lower urinary tract symptoms (LUTS) severity. The aim of this study was to investigate the effects of RSV in patients with small prostate volume and LUTS. Sixty-four patients with PF were randomized either to RSV therapy (group $A=32$ patients) or placebo (group $B=32$ patients). At baseline (T0) and after 2-months (T2), patients of both groups underwent administration of NIH-Chronic Prostatic Symptom Index (NIH-CPSI) and International Prostate Symptom Score (IPSS) questionnaires for prostatitis and LUTS, respectively, and Expressed Prostatic Secretion (EPS) assays. After two months, only, group A patients treated with RSV showed significant symptomatic improvement of all NIH-CPSI and IPSS subscale scores, as well as a better EPS assay after prostate massage, in terms of high amount of prostatic volume and reduced white blood cells counts. Our data suggested pharmacological advantage after 2-month treatment with RSV in selected patients with PF for the treatment of voiding and storage complaints.
\end{abstract}

Key words: Prostate fibrosis; small prostate volume; Meares and Stamey test; LUTS; IPSS; NIH-CPSI; Resveratrol

\section{Introduction}

Prostatic inflammation has been suggested to be a major etiological factor for benign prostatic hyper-plasia (BPH) and lower urinary tract symptoms (LUTS). End stage of inflammatory diseases results in fibrosis, characterized by the excessive deposition of collagen. Growing evidence shows that the degree of inflammation is correlated with symptoms severity and disease progression of $\mathrm{BPH}$ (nondependent prostate volume), indicating the heterogeneity of $\mathrm{BPH}$ disease [1].

Studies in animal and human support the hypothesis that the development of fibrosis could be a reversible process when the cause is removed or suppressed in various tissues, including kidneys or liver $[2,3]$.

Resveratrol (RSV) is a nutraceutical belonging to stilbenoid group, widely distributed in the plant kingdom and with several therapeutic effects. RSV is found in grapes, nuts, berries, and various other plants. Aside the various dietary sources, the RSV supplements also contain the cis- and trans-isomers of this phenolic compound, although trans-RSV is the principal form found. The trans-form shows greater stability and more biological activity than the cis-form. RSV in vivo is characterized by rapid metabolism and low bioavailability.

This molecule has been mainly studied as a complementary therapy against cardiovascular and brain disorder [4-7].

Apart from its cardiologic and neuroprotective affects, RSV also exerts anticancerogenic, antiviral, anti-inflammatory and antioxidant properties [8]. This last two characteristics allow RSV to be a potential 
treatment of chronic pathologies in aging related diseases.

Previous experimental studies identified that RSV can improve the outcome of prostatitis, since RSV treatment represses and reverses prostate fibroblast to myofibroblast phenoconversion in vitro $[9,10]$.

Albeit in vitro studies and animal models, as well as the pre-clinical evidence have demonstrated the anti-inflammatory effects of RSV, the clinical results are not as promising as the pre-clinical data and substantial conflicting data exist [11-14].

The majority of clinical studies have been designed and conducted in order to evaluate diverse metabolic outcomes. Moreover, approximately half of the published studies find an anti-inflammatory effect, and among these, some find an improvement of insulin sensitivity, whereas the other half of studies are unable to detect any anti-inflammatory effect of RSV.

Prostate fibrosis (PF) represents a particular inflammatory condition of chronic prostatitis $(\mathrm{CP})$ strongly associated with impaired urethral function through fibrotic changes in periurethral prostatic tissues $[12,13]$.

In vitro and in vivo studies have addressed to RSV promising effects on the pathogenetic mechanisms of fibrosis not only via inflammation but also via the mast cells suppression and interfering to TGF- $\beta / W n t / \beta$-catenin pathway $[14,15]$.

Therefore, the aim of this study was to investigate the therapeutic effect of RSV in patients with small prostate volume and LUTS.

\section{Materials and Methods}

\section{Subjects}

This observational study was conducted at the Andrology and Endocrinology Unit Clinic, Policlinic University of Catania (Catania, Italy), between February 2017 and July 2018. Sixty-four selected male outpatients (median age: 35 years, range: $30-49$ years) with a diagnosis of chronic inflammatory prostatitis (NIH type IIIa) and suggestive multiple symptoms and signs of prostatic fibrosis were enrolled in this study.

The diagnosis of NIH type IIIa variant fibrotic was made 6-12 months before the patients were included in this study.

All patients and controls underwent collection of their clinical history, administration of NIH-Chronic Prostatitic Symptom Index (NIH-CPSI) and International Prostate Symptom Score (IPSS) questionnaires for prostatitis and LUTS, respectively, and a physical examination [16].
The clinical characteristics of patients are described in the Table 1.

Table 1. Clinical characteristics and variables in men with prostate fibrosis before the treatment (group A) or placebo (group B)

\begin{tabular}{llll}
\hline & Group A (n=32) & Group B (=32) & $P$ value \\
\hline Age (years) & $35(30-49)$ & $35(30-49)$ & $\mathrm{ns}$ \\
Prostate volume (ml) & $28.4(22-30)$ & $27.1(22-30)$ & $\mathrm{ns}$ \\
PSA (ng/mL) & $2.0(1.3-2.5)$ & $2.0(1.4-2.4)$ & $\mathrm{ns}$ \\
PVR (ml) & $49(5-70)$ & $45(5-65)$ & $\mathrm{ns}$ \\
Total IPSS score & $19.5(9-24)$ & $19.0(9-24)$ & $\mathrm{ns}$ \\
$\begin{array}{l}\text { No. of patients with severe symptoms } \\
\text { (overall score }>\text { 20) (\%) }\end{array}$ & $11(34.3 \%)$ & $10(31.2 \%)$ & $\mathrm{ns}$ \\
$\begin{array}{l}\text { Total NIH-CPSI score } \\
\begin{array}{l}\text { Periurethral prostatic calcification } \\
\text { (diameter }>3 \text { mm) at TRUS }\end{array}\end{array}$ & $17.5(14-22)$ & $18.0(14-23)$ & $\mathrm{ns}$ \\
$\begin{array}{l}\text { Mean number (range) } \\
\text { Mean diameter (mm) (range) }\end{array}$ & $7(2-4)$ & & \\
$\begin{array}{l}\text { WBC on EPS after prostate massage or } \\
\text { VB3 (counts/hpf) }\end{array}$ & $11(8-16)$ & $10(8-15)$ & $\mathrm{ns}$ \\
\hline
\end{tabular}

Values are presented as mean \pm standard deviation. $\mathrm{ns}=$ not significant difference; Abbreviations: PSA: serum prostate specific antigen; PVR: postvoid residual urine, IPSS: International Prostate Symptom Score. IPSS: international prostate symptom score; hpf: high power field; NIH-CPSI: National Institutes of Health Chronic Prostatitis Symptom Index; TRUS: Transrectal ultrasonography; EPS: expressed prostatic secretion; WBC: white blood cell.

\section{Inclusion criteria for diagnostic symptoms}

Since it is well known that when inflammation mainly periurethral in the prostate evolved in fibrosis, this leads the progression of urinary dysfunction, for the purpose of this study, we adopted the following diagnostic criteria:

- Clinical documented history of recurrent urinary tract infections (UTI) who may be asymptomatic between episodes or may present chronic genitourinary pain for more than 3 months according to the European Association of Urology (EAU) guidelines [17];

- Validated questionnaire for IPSS National Institutes of Health Chronic Prostatitis Symptom Index (NIH-CPSI), a self-reported questionnaire widely used to assess Chronic Prostatitis (CP/ CPSI) patients and IPSS for diagnosis of LUTS. A total NIH-CPSI score $\geq 8$ was considered indicative of prostatitis, at baseline;

- LUTS encompasses a wide range of symptoms, categorized by the International Continence Society (ICS) as storage, voiding, and postmicturition. The severity of LUTS was assessed using the IPSS, Each of the questions is rated from 0 (not at all) to 5 (almost always), and according to the total symptom score, the severity of LUTS can be graded as mild (0-7), moderate (8-19) or severe (20-35), since a total IPSS $\geq 8$ points was considered to indicate the presence of LUTS [18]; 
- Proven chronic inflammatory prostatitis (NIH type IIIa), was diagnosed when no infection was detected through urine culture, sperm culture or from the expressed prostate secretion (EPS) after prostatic massage [21].

A patient was assigned to the NIH category IIIa group if at the Meares-Stamey four-glass test, the white blood cell (WBC) count in the EPS was equal to or greater than 10 per high power field (HPF) or when the WBC count in the voided $5-10 \mathrm{ml}$ urine after prostatic massage (postmassage voided urine - VB3 fraction of the Stamey test) was equal to or greater than 5 per HPF [20,21].

- Abnormal signs at physical examination and transrectal ultrasound (TRUS) suggestive of fibro-sclerotic prostatitis, as previously reported [22]. At the end of this study, we arbitrarily chose patients with small prostate volume $(<30$ $\mathrm{ml}$ ) who displayed 2 or more abnormalities for each lobe of the prostate, such as multiple areas of hypoechogenicity (associated with edema) and hyperechogenicity (associated with areas of calcification), without additional ultrasound abnormal signs at the seminal vesicles. In the present study, only the larger prostatic calculi (with the diameter over $3 \mathrm{~mm}$ ) with more echogenic foci, that caused acoustic shadowing, were considered significant prostatic calcification. This last criterion has been adopted according to Park et al. and colleagues [20], who reported that prostatic inflammatory changes were closely associated with this type of calcification. Instead, hyperechoic areas without shadowing and tiny stippled calcifications $(<3$ $\mathrm{mm}$ in largest diameter) were not considered as prostatic calculi for the purpose of this analysis.

- Completely absent or low expressed prostate secretion after prostate massage at the Meares-Stamey four-glass test, performed during the diagnostic work-up of prostatitis [23].

\section{Exclusion criteria for diagnostic symptoms}

Exclusion criteria were as follows

- Conditions that were potential LUTS inducing factors, such as: patients aged $>50$ years in order to exclude the LUTS of benign prostatic hyperplasia $(\mathrm{BPH})$; clinically apparent bladder or prostate cancer; neurologic disease that could influence voiding symptoms; uncontrolled diabetes mellitus; history of a previous lower urinary tract surgery; history of radiotherapy to the pelvis;

- History of chronic bacterial prostatitis (NIH type II) with a positive bacteriological finding at sperm culture or at the Meares-Stamey four-glass test;

- Subjects suffering from chronic or acute illness that could interfere with the study, who were taking medications that could interfere in the study, such as: anti-inflammatory drugs, proton pump inhibitors (PPIs), antidepressants, and antispasmodic agents, and who consumed antibiotics in the four weeks prior the study;

- Obesity. Defined as a body mass index (BMI) greater than or equal to $30 \mathrm{~kg} / \mathrm{m}^{2}$ );

- Subjects affected by major concomitant diseases, with known anatomical abnormalities of the urinary tract or with evidence of other urological diseases, and with residual urine volume of $>100$ $\mathrm{mL}$ resulting from bladder outlet obstruction;

- Patients with a history of prostatitis treatments.

\section{Outcome measures and methods}

\section{Primary outcome measures}

The primary outcome of this study were the changes in the NIH-CPSI total score and IPSS total score, both measured at baseline (T0) and on the end of $2^{\text {nd }}$ month (T2).

\section{Secondary outcome measures}

The secondary outcome included:

- The assessment at T0 and T2 of change in the subtotal NIH-CPSI, including symptoms such as pain or discomfort, urination, impact of symptom, and the subscale about Quality of life (QOL), and subtotal IPPS/QOL scores, subcategorized into: voiding (items $1,3,5,6$ ), storage (items 2, 4, 7) and postmicturition symptoms;

- Changes in EPS assays obtained after prostatic massage.

\section{Treatment}

Patients in both groups of prostatic fibrosis were allocated at random into two subsets which were assigned either to the treatment with RSV 19.8 (group $\mathrm{A}=32$ ), or placebo in tablet (group $\mathrm{B}=32$ ) both one tablet twice daily for two consecutive months.

Randomization was achieved using a computer program. The first random set of numbers was assigned to treatment, including together 32 patients with inflammatory fibrotic prostatitis (intervention group). The second random set of 32 patients with inflammatory fibrotic prostatitis received placebo (control group).

Study subjects were informed of the risks and requirements of the study, and the study protocol was 
approved by the internal Institutional Review Board and informed written consent was obtained from each patient.

\section{Statistical analyses}

Statistical analysis was performed with SPSS ver. 12.0 (SPSS Inc., Chicago, IL, USA).

Quantitative data were expressed as median and range, and qualitative data were expressed as percentages throughout the study. Intragroup differences in NIH-CPSI or IPSS questionnaire scores before/after therapy were analysed using Wilcoxon's signed rank test. Mann-Whitney $U$ tests, or the chi-square test or Fisher's exact test were used for analyses that compared different groups. A statistically significant difference was accepted when $p$ value was lower than 0.05 .

\section{Results}

The demographic and baseline characteristics of the variables studied in both patient groups are shown in Table 1. There was no significant difference between the two groups of total 64 patients, eligible for the comparative study analysis: treatment with RSV (intervention group or group A) or placebo (control group or group B) (Table 1).

\section{Comparison between RSV treated with placebo treated in primary outcomes}

In the treated group we observed that the total
NIH-CPSI score were reduced from 17.5 to 14.0 and the total IPSS score from 19.5 to 12.5 , respectively before vs after treatment. The total NIH-CPSI score and the total IPSS score in placebo group did not show significant modifications after the treatment. The comparison between RSV treated and placebo showed a significant reduction in NHI-CIPSI score and in total IPSS score (Table 2).

Both groups with prostate fibrosis at $\mathrm{T} 0$ showed a high percentage of patients with completely absent or low amount of prostatic secretion after prostate massage (Stamey test), with significantly high WBC counts per high power field in VB3, corroborating more likely the diagnosis of inflammatory prostatitis (NIH, category IIIA) (Table 2). At T2, after treatment and prostate massage, the group A had a better EPS, in terms of increased amount of prostate volume secreted and WBC counts per high power field. Significantly lower than those found in matched group in the pretreatment (Table 2).

Before the treatment (T0), total NIH-CPSI scores did not show any significant difference between the two groups. After 2 months of treatment (T2), the total score changed significantly in both groups $(p<0.05)$. In the treated group, the total NIH-CPSI score reduced from 17.5 (range 14-22) to 14.0 (range 9-19) but was unmodified in the placebo group (Table 2).

Table 2. Outcome measures analysis as a function of time of the treatment (group A) or placebo (group B) with RSV in studied patients with prostate fibrosis. Values were expressed as mean and range of percentages (in parentheses)

\begin{tabular}{|c|c|c|c|c|}
\hline \multirow[b]{3}{*}{ Study time-point } & \multicolumn{4}{|c|}{ PROSTATE FIBROSIS } \\
\hline & \multicolumn{2}{|c|}{ Group A (intervention group) } & \multicolumn{2}{|c|}{ Group B (placebo group) } \\
\hline & T0 $(n=32)$ & $\mathrm{T} 2(\mathrm{n}=32)$ & T0 $(n=32)$ & $\mathrm{T} 2(\mathrm{n}=32)$ \\
\hline \multicolumn{5}{|l|}{ Primary outcome } \\
\hline \multicolumn{5}{|l|}{ Symptoms } \\
\hline Total NIH-CPSI score & $17.5(14-22)$ & $14.0^{* \circ}(9-19)$ & $18.0(14-23)$ & $19.5(13-24)$ \\
\hline Total IPSS score & $19.5(9-24)$ & $12.5^{* \circ}(7-22)$ & $19.0(9-24)$ & $19.0(12-24)$ \\
\hline No. with severe (IPPS score >20) symptoms & $5(15.6 \%)$ & $4(12.5 \%)$ & $6(18.7 \%)$ & $7(21.8 \%)$ \\
\hline \multicolumn{5}{|l|}{ Signs } \\
\hline EPS: volume $(\mathrm{ml})$ after prostate massage & $0.05(0-0.1)$ & $0.3^{* \circ}(0-0.45)$ & $0.05(0-0.1)$ & $0.05(0-0.1)$ \\
\hline No. patients without EPS after prostate massage & $28(87.5 \%)$ & $13(40.6 \%)^{* \circ}$ & $29(90.6 \%)$ & $29(90.6 \%)$ \\
\hline WBC on EPS after prostate massage or VB3 & $11(8-16)$ & $6^{* 0}(5-9)$ & $10(8-15)$ & $12(9-16)$ \\
\hline \multicolumn{5}{|l|}{ Secondary outcome } \\
\hline \multicolumn{5}{|l|}{ Subtotal NIH-CPSI score } \\
\hline Pain subscale & $9.4(8-14)$ & $7.8^{* \circ}(4-10)$ & $10.8(8-14)$ & $10.7(7-13)$ \\
\hline Urinary subscale & $5.0(3-6)$ & $3.3^{* \circ}(1-4)$ & $5.8(3-7)$ & $4.0(2-5)$ \\
\hline Quality-of-Life (QoL) subscale & $3.7(3-5)$ & $2.7^{\star \circ}(2-4)$ & $4.2(3-6)$ & $3.8(2-6)$ \\
\hline \multicolumn{5}{|l|}{ Subtotal IPSS score } \\
\hline Storage IPSS (items $2,4,7$ ) & $7.0(5-12)$ & $5.5^{* \circ}(3-9)$ & $7.0(5-12)$ & $7.0(6-11)$ \\
\hline Voiding IPSS (items 1, 3, 5 and 6) & $9.5(8-20)$ & $5.0^{* \circ}(4-12)$ & $9.0(8.0-20)$ & $9.5(8-19)$ \\
\hline QoL subscale & $3.0(2.0-4)$ & $2.0^{* \circ}(1.4-3)$ & $3.0(2.0-4)$ & $3.0(2.0-4.0)$ \\
\hline
\end{tabular}

$\mathrm{T} 0=$ before the treatment; $\mathrm{T} 2=2$ months afterward;

${ }^{*} p<0.05$ intragroup comparison, Group A T2 vs. Group A T0.

${ }^{\circ} p<0.05$ intergroup comparison, Group A T2 vs. Group B T2. 
In RSV treated group, we observed a significant reduction in pain subscale, in urinary subscale and in QoL subscale (subtotal NIH-CPSI score) and in storage IPSS, in voiding IPSS and in QoL subscale (subtotal IPSS score) comparing before vs. after treatment. No significant modifications were shown in placebo treated group after the treatment. The comparison between Treated vs. Placebo groups showed a significant difference in both the subtotal NIH-CPSI score and subtotal IPSS score (Table 2). Hence, although no significant difference existed between the two groups at baseline in all NIH-CPSI subscale score, at T2 significant decreases of pain, urination, and quality of life were shown in the RSV group (group A), whereas these same subscales scores were unchanged in the placebo group (group B) (Table 2). Regarding obstructive (LUTS) symptoms, IPSS score showed no significant difference between the groups A and B at baseline (T0). At T2, compared with baseline symptoms significant decreases were observed in the total IPSS total score, IPSS-storage, IPSS-voiding, IPSS-QOL, in patients of group A (intervention group), but were unmodified in the placebo group.

\section{Discussion}

The results of this trial show that the treatment with RSV decreased PF and LUTS, increasing the quality of life. In fact, we observed a decrease 3,5 points in total NIH-CPSI score, 7,0 points in total IPSS score and the increase of $46.9 \%$ in EPS after prostate massage.

PF is a consequence of chronic inflammation, causing hyperplasia of cells with a smooth muscle cell phenotype and altering the turnover of collagen and other extracellular matrix components.

Agents that prevent or slow the proliferation of smooth muscle cells and decrease excessive collagen deposition may provide new therapeutic strategies or be used as supplement to the current immunemodulatory therapy of fibrostenosing [24].

The decrease of the primary outcomes is associated with a reduction of secondary outcomes: 1.6 points pain, 1.7 points urinary subscale, 1.5 points storage IPSS, 4.5 points voiding IPSS (Table 2).

Chronic inflammatory prostatitis (NIH, cat IIIA) $(\mathrm{CP})$, a common disease in urology, has been suggested to contribute to the aetiology of lower urinary tract symptoms (LUTS) by inducing fibrotic changes in periurethral prostatic tissues and promote urethral stiffness and LUTS [25].

In clinical practice, approximately half of LUTS patients have a relatively small $(30 \mathrm{~mL}$ or less) prostate volume (small PV), indicating the heterogeneity of this disease [26]. Therefore, the classical dynamic and static components of prostate cannot explain the exact pathophysiology of small PVLUTS [27, 28]. Thus, prostatic inflammation-induced fibrosis has gained increasing attention as a major contributing factor in the pathogenesis of small prostate volume and LUTS. In these patients, the co-presence of multiple prostatic calcifications having larger prostatic calculi with the diameter over $3 \mathrm{~mm}$ has a pathological connection with prostatic inflammatory changes and fibrosis [29,30]. In particular, inflammation of the periurethral area, can contribute, via an excess of collagen deposition and fibrosis in the prostate, to impair urethral function, with urethral stiffness which in turn maximizes induction of LUTS [31-32].

In a previous study, we described three diagnostic categories (prostatitis, prostate-vesiculitis and prostate-vesiculo-epididymitis), distinguishing into two major variants, with group-specific ecostructural findings called hypertrophic-congestive, and fibro-sclerotic. In the present study we enrolled patients who responded precisely to diagnostic criteria of prostatitis inflammation-induced fibrosis. The present study investigated changes related to a 2-months treatment with RSV in patients with prostate fibrosis, through the analysis of irritative and obstructive symptoms as well as measures of expressed prostate secretion assays obtained after prostatic massage. Here, the intervention group of patients treated with RSV showed significant symptomatic improvement of all NIH-CPSI and IPSS subscale scores, as well as a better EPS assay after prostate massage, in terms of high amount of prostatic volume and reduced white blood cells counts.

RSV has been shown to reduce inflammation to inhibit fibrosis in cultured vascular smooth muscle cells in rat model as well as to inhibit intimal hyperplasia in an in vivo model of vascular injury [33-35].

RSV tested in an animal model of chronic prostatitis resversed mast cell activation, decreased collagen content, the maximum capacity of the bladder, residual urine volume, maximum voiding pressure and the expression levels of a-SMA, a marker of fibrosis. It is possible that these effects have been due to the decreased activity of TGF- $\beta /$ Wnt/ $\beta$-catenin signaling, involved in the mast cell activation and fibrosis process, and SCF/c-Kit signaling pathway, related to the proliferation and differentiation of cells [36, 37]. The inactivation of these pathways seems caused by the activation of SIRT1 pathway as a result of RSV administration [38].

Pyo et al. (2017) found similar decreased histopathological changes in prostate when mice with 
estradiol-induced prostatitis were treated with RSV [39].

One of main problem of RSV formulation is the low bioavailability in humans [40].

The absorption of the dietary relevant $25 \mathrm{mg}$ oral dose was at least $70 \%$, with peak plasma levels of RSV, metabolites of $491 \pm 90 \mathrm{ng} / \mathrm{ml}$ and a plasma half-life of $9.2 \pm 0.6$ hours. Most of the oral dose was recovered in urine. Although the systemic bioavailability of RSV is low, accumulation of RSV and its potentially active metabolite may still produce tumour preventive and other effects [41, 42].

The differences between the results in clinical trials on different pathological conditions may be attributable to differences in the study populations. Genders, age, dosage of RSV, length of the study, and the health status of the participants have been suggested to be factors that may influence the results. Especially, a large difference has been found in the concentration and dosage of RSV among the clinical studies. No consensus exists on which concentration of RSV may be ideal in relation to anti-inflammatory effects.

In our study RSV plays an important role to reduce the chronic inflammation that promote excessive collagen deposition in the prostate and is at least part reversible [43].

\section{Conclusions}

Currently no therapeutic agents have shown a specifically curative activity on prostatic fibrosis.

Although to the best of our knowledge, no reports have investigated the effects of RSV on reversibility of fibrosis in the prostate.

The results of the present study suggest that RSV may be considered as a potential target for the treatment of LUTS in patients with small prostate volume and prostate fibrosis, through a reduction of the progression urinary dysfunction.

\section{Competing Interests}

The authors have declared that no competing interest exists.

\section{References}

1. Rodriguez-Nieves JA, Macoska JA. Prostatic fibrosis, lower urinary tract symptoms, and BPH. Nat Rev Urol. 2013; 10:546-50. doi: 10.1038/ nrurol.2013.149.

2. Iredale JP, Benyon RC, Pickering J, McCullen M, Northrop M, Pawley S, Hovell C, Arthur MJ.Mechanisms of spontaneous resolution of rat liver fibrosis. Hepatic stellate cell apoptosis and reduced hepatic expression of metalloproteinase inhibitors. J Clin Invest. 1998; 102(3):538-49. DOI:10.1172/JCI1018.

3. Wahab A, Gao K, Jia C, Zhang F, Tian G, Murtaza G, Chen J. Significance of Resveratrol in Clinical Management of Chronic Diseases. Molecules. 2017; 22(8):1329. pii: E1329. doi: 10.3390/molecules22081329.

4. Barone R, Rizzo R, Tabbì G, Malaguarnera M, Frye RE, Bastin J. Nuclear Peroxisome Proliferator-Activated Receptors (PPARs) as Therapeutic Targets of Resveratrol for Autism Spectrum Disorder. Int J Mol Sci. 2019; 20(8):1878. pii: E1878. doi: 10.3390/ijms20081878.
5. Malaguarnera L. Influence of Resveratrol on the Immune Response. Nutrients. 2019;11(5):946. pii: E946. doi: 10.3390/nu11050946.

6. Tomé-Carneiro J, Larrosa M, González-Sarrías A, Tomás-Barberán FA, García-Conesa MT, Espín JC. Resveratrol and clinical trials: the crossroad from in vitro studies to human evidence. Curr Pharm. 2013; 19(34):6064-93. Review.

7. Pennisi M, Bertino G, Gagliano C, Malaguarnera M, Bella R, Borzì AM, Madeddu R, Drago F, Malaguarnera G.Resveratrol in Hepatitis C Patients Treated with Pegylated-Interferon- $a-2 b$ and Ribavirin Reduces Sleep Disturbance. Nutrients. 2017; 9(8):897. pii: E897. doi: 10.3390/nu9080897.

8. Malaguarnera $M$, Khan $\mathrm{H}$, Cauli $\mathrm{O}$. Resveratrol in Autism Spectrum Disorders: Behavioral and Molecular Effects. Antioxidants (Basel). 2020; 9(3):188. pii: E188. doi: 10.3390/antiox9030188. Review.

9. Gharaee-Kermani M, Moore BB, Macoska JA. Resveratrol-mediated repression and reversion of prostatic myofibroblast phenoconversion. PLoS One. 2016;11:e0158357. doi: 10.1371/journal.pone.0158357.

10. Salehi B, Mishra AP, Nigam M, Sener B, Kilic M, Sharifi-Rad M, Fokou PVT, Martins N, Sharifi-Rad J. Resveratrol: A Double-Edged Sword in Health Benefits. Biomedicines. 2018; 6(3):91. pii: E91. doi: 10.3390/ biomedicines6030091.

11. He Y, Zeng H, Yu Y, Zhang J, Zeng X, Gong F, Duan X, Liu Q, Yang B. Resveratrol improved the progression of chronic prostatitis via the downregulation of c-kit/SCF by activating Sirt1. J Agric Food Chem. 2017; 65:5668-5673. doi: 10.1021/acs.jafc.7b01879.

12. Ma J, Gharaee-Kermani M, Kunju L, Hollingsworth JM, Adler J, Arruda EM, Macoska JA. Prostatic fibrosis is associated with lower urinary tract symptoms. The Journal of Urology. 2012; 188(4):1375-1381. doi: 10.1016/ j.juro.2012.06.007.

13. Cantiello F, Cicione A, Salonia A, Autorino R, Tucci L, Madeo I, Damiano R. Periurethral fibrosis secondary to prostatic inflammation causing lower urinary tract symptoms: a prospective cohort study. Urology. 2013; 81(5):1018-1023. doi: 10.1016/j.urology.2013.01.053.

14. He Y, Zeng HZ, Yu Y, Zhang JS, Duan X, Zeng XN, Gong FT, Liu Q, Yang B. Resveratrol improves prostate fibrosis during progression of urinary dysfunction in chronic prostatitis. Environ Toxicol Pharmacol. 2017; 54:120124. doi: 10.1016/j.etap.2017.06.025.

15. Galvano F, Malaguarnera M, Vacante M, Motta M, Russo C, Malaguarnera G,D'Orazio N, Malaguarnera L. The physiopathology of lipoprotein (a). Front Biosci (Schol Ed). 2010; 2:866-75. Review.

16. Grabe M., Bjerklund-Johansen T.E., Botto H., Çek M., Naber K.G., Pickard R.S., Tenke P., Wagenlehner F., Wullt B. Guidelines on Urological Infections. European Association of Urology; Arnhem, The Netherlands. 2012; p. 66.

17. Litwin, MS; McNaughton-Collins, M.; Fowler, FJ, Jr.; Nickel, JC; Calhoun, EA; Pontari, MA; Alexander, RB; Farrar, JT; O'Leary, MP The NIH Chronic Prostatitis Symptom Index (NIH-CPSI): Development and validation of a new outcomes measure. J. Urol. 1999; 162:364-368. DOI:10.1016/s00225347(05)68562-x

18. Trujillo KA, Heaphy CM, Mai M, Vargas KM, Jones AC, Vo P, Butler KS, Joste NE, Bisoffi M, Griffith JK. Markers of fibrosis and epithelial to mesenchymal transition demonstrate field cancerization in histologically normal tissue adjacent to breast tumors. Int J Cancer. 2011; 129:1310-1321. doi: 10.1002/ ijc. 25788.

19. Barry MJ, Fowler FJ, Jr, O'Leary MP, Bruskewitz RC, Holtgrewe HL, Mebust WK, et al. The American Urological Association symptom index for benign prostatic hyperplasia. The measurement Committee of the American Urological Association. J Urol. 1992; 148:1549-1557. discussion 1564. DOI: 10.1016/s0022-5347(17)36967-7.

20. La Vignera S, Vicari E, Condorelli R, D'Agata R, Calogero AE. Hypertrophic-congestive and fibro-sclerotic ultrasound variants of male accessory gland infection have different sperm output. J Endocrinol Invest. 2011; 34(10 e): 330-5. DOI:10.1007/BF03346729.

21. Krieger JN, Nyberg L Jr, Nickel JC. NIH consensus definition and classification of prostatitis. JAMA. 1999; 282: 236-237. doi:10-1001/pubs.JAMA-ISSN0098-7484-282-3-jac90006.

22. Meares EM, Stamey TA. Bacteriologic localization patterns in bacterial prostatitis and urethritis. Invest Urol. 1968; 5:492-518.

23. Schaeffer AJ, Knauss JS, Landis JR, Propert KJ, Alexander RB, et al. Leukocyte and bacterial counts do not correlate with severity of symptoms in men with chronic prostatitis: the National Institutes of Health Chronic Prostatitis Cohort Study. J Urol. 2002; 168: 1048-1053. DOI:10.1097/01.ju. 0000024762.69326

24. Garcia P, Schmiedlin-Ren P, Mathias JS, Tang H, Christman GM, Zimmermann EM. Resveratrol causes cell cycle arrest, decreased collagen synthesis, and apoptosis in rat intestinal smooth muscle cells. Am J Physiol Gastrointest Liver Physiol. 2012; 302(3):G326-35. doi: 10.1152/ ajpgi.00083.2011. Epub 2011 Nov 3. PubMed.

25. Latteri S, Catania VE, Malaguarnera G, et al. Carcinoembryonic Antigen Serum Levels in Nonmelanoma Skin Cancer. Biomedicines. 2018; 6(1):24. Published 2018 Feb 23. doi:10.3390/biomedicines6010024.

26. Zaitsev AV, Pushkar DY, Khodyreva LA, Dudareva AA. [Bacterial prostatitis and prostatic fibrosis: modern view on the treatment and prophylaxis]. Urologiia. 2016; 4:114-120.

27. Nickel JC, Roehrborn CG, O'Leary MP, Bostwick DG, Somerville MC, Rittmaster RS. The relationship between prostate inflammation and lower urinary tract symptoms: examination of baseline data from the REDUCE trial. Eur Urol. 2008; 54:1379-84. DOI:10.1016/j.eururo.2007.11.026 
28. Malaguarnera M, Vacante M, Russo C, et al. Rosuvastatin reduces nonalcoholic fatty liver disease in patients with chronic hepatitis $C$ treated with a-interferon and ribavirin: Rosuvastatin reduces NAFLD in HCV patients. Hepat Mon. 2011; 11(2):92-98.

29. Abrams P, Cardozo L, Fall M, Griffiths D, Rosier P, Ulmsten U, et al. The standardization of terminology of lower urinary tract function: report from the standardization sub-committee of the International Continence Society. Neurourol Urodyn. 2002; 21:167-178.

30. Gomes CM, Nunes RV, Araújo RM, Sacomani CR, Trigo-Rocha FE, Bruschini $\mathrm{H}$, et al. Urodynamic evaluation of patients with lower urinary tract symptoms and small prostate volume. Urol Int. 2008; 81:129-34. doi: 10.1159/ 000144049.

31. Park B, Choo SH. The burden of prostatic calculi is more important than the presence. Asian J Androl 2017; 19:482-485. doi: 10.4103/1008-682X.181193.

32. Han JH, Lee JY, Kwon JK, Lee JS, and Cho KS. Clinical Significance of Periurethral Calcification According to the Location in Men With Lower Urinary Tract Symptoms and a Small Prostate Volume. Int Neurourol J. 2017; 21(3): 220-228. doi: 10.5213/inj.1732732.366.

33. Poussier B, Cordova AC, Becquemin JP, Sumpio BE. Resveratrol inhibits vascular smooth muscle cell proliferation and induces apoptosis. J Vasc Surg. 2005; 42(6):1190-7.

34. Zou J, Huang Y, Cao K, Yang G, Yin H, Len J, Hsieh TC, Wu JM. Effect of resveratrol on intimal hyperplasia after endothelial denudation in an experimental rabbit model. Life Sci. 2000; 68(2):153-63.

35. Ghosh AK, Varga J. The transcriptional coactivator and acetyltransferase p300 in fibroblast biology and fibrosis. J Cell Physiol. 2007; 213(3):663-71. Review.

36. Zeng H, He Y, Yu Y, Zhang J, Zeng X, Gong F, Liu Q, Yang B. Resveratrol improves prostate fibrosis during progression of urinary dysfunction in chronic prostatitis by mast cell suppression. Mol Med Rep. 2018; 17(1):918-924. doi: $10.3892 / \mathrm{mmr} .2017 .7960$.

37. Yu Y, Jiang J, He Y, Wang W, Shen C, Yang B. Resveratrol improves urinary dysfunction in rats with chronic prostatitis and suppresses the activity of the stem cell factor/c-Kit signaling pathway. Mol Med Rep. 2017; 16(2): 1395-1400. doi: 10.3892/mmr.2017.6721. Epub 2017 Jun 8

38. He Y, Zeng H, Yu Y, Zhang J, Duan X, Liu Q, Yang B. Resveratrol improves smooth muscle carcinogenesis in the progression of chronic prostatitis via the downregulation of c-kit/SCF by activating Sirt1. Biomed Pharmacother. 2017; 95:161-166. doi: 10.1016/j.biopha.2017.08.064. Epub 2017 Sep 12.

39. Pyo KH, Lee YW, Lee SH, Xin CF, Shin JH, Shin EH. Preventive Effects of Resveratrol-enriched Extract of Peanut Sprout on Bacteria- and Estradiolinduced Prostatitis in Mice. Nat Prod Commun. 2017 ;12(1):73-78.

40. Peltz L, Gomez J, Marquez M, Alencastro F, Atashpanjeh N, Quang T, Bach T,Zhao Y. Resveratrol exerts dosage and duration dependent effect on human mesenchymal stem cell development. PLoS One. 2012; 7(5):e37162. doi: 10.1371/journal.pone.0037162. Epub 2012 May 16.

41. Walle T, Hsieh F, DeLegge MH, Oatis JE Jr, Walle UK.. High absorption but very low bioavailability of oral resveratrol in humans. Drug Metab Dispos. 2004; 32(12):1377-82. Epub 2004 Aug 27.

42. Sharma S, Chopra K, Kulkarni SK, Agrewala JN. Resveratrol and curcumin suppress immune response through CD28/CTLA-4 and CD80 co-stimulatory pathway. Clin Exp Immunol. 2007;147(1):155-63.

43. Poulsen MM, Fjeldborg K, Ornstrup MJ, Kjær TN, Nøhr MK, Pedersen SB. Resveratrol and inflammation: Challenges in translating pre-clinical findings to improved patient outcomes. Biochimica et Biophysica Acta (BBA) Molecular Basis of Disease. 2015; 1852(6): 1124-1136. doi: 10.1016/j.bbadis.2014.12.024. 